\title{
Mass-independent isotope effect in the earliest processed solids in the solar system: A possible chemical mechanism
}

\author{
R. A. Marcus \\ Noyes Laboratory of Chemical Physics, California Institute of Technology, Pasadena, California 91124
}

(Received 8 July 2004; accepted 12 August 2004)

\begin{abstract}
A major constraint is described for a possible chemical origin for the "mass-independent" oxygen isotope phenomenon in calcium-aluminum rich inclusions (CAIs) in meteorites at high temperatures $(\sim 1500-2000 \mathrm{~K})$. A symmetry-based dynamical $\eta$ effect is postulated for $\mathrm{O}$ atom-monoxide recombination on the surface of growing CAIs. It is the surface analog of the volume-based $\eta$ effect occurring in a similar phenomenon for ozone in the gas phase [Y. Q. Gao, W. C. Chen, and R. A. Marcus, J. Chem. Phys. 117, 1536 (2002), and references cited therein]: In the growth of CAI grains an equilibrium is postulated between adsorbed species $X \mathrm{O}(a d s)+\mathrm{O}($ ads $) \rightleftarrows X \mathrm{O}_{2}^{*}($ ads $)$, where $X \mathrm{O}_{2}^{*}(a d s)$ is a vibrationally excited adsorbed dioxide molecule and $X$ can be $\mathrm{Si}, \mathrm{Al}, \mathrm{Ti}$, or other metals and can be $\mathrm{C}$ for minerals less refractory than the CAIs. The surface of a growing grain has an entropic effect of many order of magnitude on the position of this monoxide-dioxide equilibrium relative to its volume-based position by acting as a concentrator. The volume-based $\eta$ effect for ozone in the earlier study is not applicable to gas phase precursors of CAIs, due to the rarity of three-body recombination collisions at very low pressures and because of the high $\mathrm{H}_{2}$ and $\mathrm{H}$ concentration in solar gas, which reduces gaseous $\mathrm{O}$ and gaseous dioxides and prevents the latter from acting as storage reservoirs for the two heavier oxygen isotopes. A surface $\eta$ effect yields $X \mathrm{O}_{2}^{*}(a d s)$ that is mass-independently rich in ${ }^{17} \mathrm{O}$ and ${ }^{18} \mathrm{O}$, and yields $X \mathrm{O}(a d s)+\mathrm{O}(a d s)$ that is mass-independently poor in the two heavier oxygen isotopes. When the $X \mathrm{O}_{2}^{*}(a d s)$ is deactivated by vibrational energy loss to the grain, it has only one subsequent fate, evaporation, and so undergoes no further isotopic fractionation. After evaporation the $\mathrm{XO}_{2}$ again has only one fate, which is to react rapidly with $\mathrm{H}$ and ultimately form ${ }^{16} \mathrm{O}$-poor $\mathrm{H}_{2} \mathrm{O}$. The other species, $\mathrm{O}(a d s)$ $+X \mathrm{O}(a d s)$, are ${ }^{16} \mathrm{O}$ rich and react with $\mathrm{Ca}(a d s)$ and other adsorbed metal atoms or metallic monoxides to form CAIs. The latter are thereby mass-independently poor in ${ }^{17} \mathrm{O}$ and ${ }^{18} \mathrm{O}$. Some $\mathrm{O}(a d s)$ used to form the minerals are necessarily in excess of the $X \mathrm{O}(a d s)$, because of the stoichiometry of the mineral, and modify the fractionation pattern. This effect is incorporated into the mechanistic and mathematical scheme. A merit of this chemical mechanism for the oxygen isotope anomaly is that only one oxygen reservoir is required in the solar nebula. It also does not require a sequestering of intermediate products which could undergo isotopic exchange, hence undoing the original isotopic fractionations. The gas phase source of adsorbed $\mathrm{O}$ atoms in this environment is either $\mathrm{O}$ or $\mathrm{H}_{2} \mathrm{O}$. As inferred from data on the evaporation of $\mathrm{Mg}_{2} \mathrm{SiO}_{4}$ taken as an example, the source of $\mathrm{O}(a d s)$ is primarily $\mathrm{H}_{2} \mathrm{O}$ rather than $\mathrm{O}$ and is accompanied by the evolution of $\mathrm{H}_{2}$. Nonisotopic kinetic experiments can determine more sharply the mechanism of condensed phase growth of these minerals. Laboratory tests are proposed to test the existence of a surface $\eta$ effect on the growing CAI surfaces at these high temperatures. (c) 2004 American Institute of Physics. [DOI: 10.1063/1.1803507]
\end{abstract}

\section{INTRODUCTION}

The earliest processed solids in the solar system, the calcium-aluminum rich inclusions (CAIs) in chondritic meteorites, are about $4.56 \times 10^{9}$ years old. ${ }^{1-5}$ The CAIs show a "mass-independent" oxygen isotope effect, namely, an equal deficiency in the heavy isotopes ${ }^{17} \mathrm{O}$ and ${ }^{18} \mathrm{O}$ relative to the mean isotopic composition of ocean water: The slope of a plot of $\left({ }^{17} \mathrm{O} /{ }^{16} \mathrm{O}\right)_{\text {sample }} /\left({ }^{17} \mathrm{O} /{ }^{16} \mathrm{O}\right)_{\text {standard }}$ versus the corresponding quantity for ${ }^{18} \mathrm{O}$ is close to 1.0 , instead of having the usual and well understood mass-dependent value close to 0.52 .

This unexpected mass-independent phenomenon, whose origin remains unknown some 30 years after its striking dis- covery by Clayton et al., ${ }^{6}$ has been the subject of numerous studies, e.g., Refs. 7-21. The phenomenon is also observed in chondrules, ${ }^{19}$ a much more extensive component of chondrites, and frequently regarded as forming slightly later than CAIs. The interest lies in what clues this unusual isotopic effect and other data ${ }^{22-41}$ can provide about the formation of the solar system. Some nonisotopic observations, for example, point to forming most CAIs in environments which vary from more oxidizing to more reducing than that of a solar gas, e.g., Refs. 42 and 43. "Dust enriched" scenarios for the initial composition of the pre-CA1 environment are often considered in the literature, e.g., Refs. 37 and 42-47, and are more oxidizing than a solar gas. However, for the 
present analysis it is the composition of the adsorbed species on the surface of the growing CAI grains, rather than that in the gas phase, which is important. It is shown in Sec. II B that the two can be very different. For brevity, the growing CAI precursor grains are referred to simply as CAIs in the following ("CAI precursors" since their formation may be followed by subsequent processing such as melting and resolidification).

If the mass-independent phenomenon has a chemical origin, which is by no means assured, it places constraints on the conditions under which the CAIs are formed. Our aim is to describe kinetic conditions which, if fulfilled, yield a mass-independent formation of CAIs, suggest laboratory tests, and make predictions.

A nucleosynthetic origin of the phenomenon was initially postulated by Clayton. ${ }^{6}$ Fractionation by self-shielding is also a possibility. ${ }^{48-50} \mathrm{~A}$ chemical origin has been proposed by Thiemens, ${ }^{51}$ who discussed various possible reactions. Arguments against the nucleosynthetic proposal include the absence of related isotopic anomalies in the same solids. $^{2}$ A nucleosynthetic galactic evolution model ${ }^{52}$ remains a viable possibility, but presently not testable. ${ }^{53}$ By far the greatest fractionation due to self-shielding would be between ${ }^{16} \mathrm{O}$ versus ${ }^{17} \mathrm{O}$ and ${ }^{18} \mathrm{O}$, because of the large difference in abundance.

Optical shielding calculations have been initiated ${ }^{54}$ and may also reveal the extent of optical fractionation between ${ }^{17} \mathrm{O}$ and ${ }^{18} \mathrm{O}$. A detailed analysis of chemical mechanisms remains to be undertaken and is the subject of the present paper.

A chemical mechanism has been documented for the mass-independent isotope effect in ozone formation ${ }^{55}$ in the laboratory and in the stratosphere, e.g., Refs. 56-58. Ozone formed by photolysis ${ }^{56-58}$ or electric discharge ${ }^{59}$ in oxygen is approximately equally enriched in ${ }^{17} \mathrm{O} /{ }^{16} \mathrm{O}$ and ${ }^{18} \mathrm{O} /{ }^{16} \mathrm{O}$. The enrichment at room temperature is about 100 parts per mil relative to the initial composition. An explanation has been given ${ }^{60-64}$ and provides insight into data on many different experiments, including those where there is extensive isotopic exchange, ${ }^{55-59}$ those where there is none,${ }^{65-68}$ the different pressure effects for each of these conditions, ${ }^{68-70}$ and experiments using oxygen heavily enriched in ${ }^{17} \mathrm{O}$ and ${ }^{18} \mathrm{O} \cdot{ }^{71-75}$ We apply the concepts here, particularly the symmetry-based $\eta$ effect described for ozone in Refs. 60-64.

The physical nature of the $\eta$ effect is summarized in Appendix A. In the present case ozone is not involved, but the chemical physics of the phenomenon ${ }^{60-64}$ would be similar for any molecule with symmetric and asymmetric isotopologs. For the CAIs, however, we shall see that a surfacebased rather than as in ozone a volume-based $\eta$ effect is required. Laboratory experiments can provide the information on whether or not such an effect exists.

The equal deficiency in ${ }^{17} \mathrm{O}$ and ${ }^{18} \mathrm{O}$ in the CAIs is as much as 50 or so per mil for the more refractory minerals. $^{7-21}$ For minerals which have a condensation temperature lower than the CAIs, as in chondrules, this deficiency is typically less, even becoming a slightly positive enrichment. ${ }^{19}$ Since the enrichments in the CAIs are opposite in sign from those in ozone formation, the problem has, in a sense, been "turned on its head." The CAI minerals are many and, in terms of readily recognizable formula units, they include hibonite $\mathrm{CaO}\left(\mathrm{Al}_{2} \mathrm{O}_{3}\right)_{6}$, anorthite $\mathrm{CaO}\left(\mathrm{Al}_{2} \mathrm{O}_{3}\right)\left(\mathrm{SiO}_{2}\right)_{2}$, spinel $\mathrm{MgO}\left(\mathrm{Al}_{2} \mathrm{O}_{3}\right)$, melilite $(\mathrm{CaO})_{2}(\mathrm{MgO})_{x}\left(\mathrm{SiO}_{2}\right)_{1+x}\left(\mathrm{Al}_{2} \mathrm{O}_{3}\right)_{1-x}$, and non-Ca, $\mathrm{Al}$ minerals such as forsterite $(\mathrm{MgO})_{2} \mathrm{SiO}_{2}$. (In minerologists' formulas the more customary designations are $\mathrm{CaAl}_{12} \mathrm{O}_{19}$, $\mathrm{CaAl}_{2} \mathrm{Si}_{2} \mathrm{O}_{8}, \ldots$ )

A local exhaustion of $\mathrm{Al}$ and $\mathrm{Ca}$ due to their limited abundance stops the formation of those CAIs. As the temperature falls, ferromagnesian silicates (chondrules) can condense with $\mathrm{Fe}$ and $\mathrm{Mg}$ as the metallic elements and perhaps with some overlap of the two depositions.

An open question is whether the sequence of minerals in these systems represents largely a condensation or an evaporation sequence. The sequences have been discussed in Refs. 44-47, 76, and 77. Any mechanism should also ultimately explain the different textural properties of the meteoritic components, as well as the presence of elements that form volatile oxides, among other observations.

The system is now much more complex than the ozone system, since many additional species and reaction steps occur. In addition to gas phase reactions there are now also evaporation and mineral-forming condensation. Even the primary act for a possible chemical mechanism is not known.

Laboratory attempts to produce a mass-independent effect of the magnitude experimentally observed in the CAIs have not yet been successful, ${ }^{78-80}$ apart from a single experiment discussed in Sec. III which showed intriguing results. No detailed theory was available to assist in the selection of experimental conditions. In the case of ozone the theory benefited from a large body of experimental data. The existing body of data on the CAIs places constraints on theory, and theoretically based laboratory experiments for forming the CAIs under controlled conditions remain to be undertaken.

The paper is organized as follows: A theory is described in Sec. II containing preliminary remarks on the model (Sec. II A), a description of the key role of the surface in shifting the position of monoxide/dioxide equilibria for adsorbed species (Sec. II B), a summary of the specific constraints imposed by the phenomenon on the theory (Sec. II C), kinetic equations (Sec. II D), and condensation kinetics (Sec. II E). An approximate equation for the resulting mass-independent isotopic enrichment is given by Eqs. (10), (12), and (13). The results are discussed and proposed experiments are given in Sec. III.

\section{THEORY}

\section{A. Model and assumptions}

We assume a system where the mass-independent fractionation is occurring in a high temperature environment $(\sim 1500-2000 \mathrm{~K})$ and at low pressures $(\sim 0.001 \mathrm{bar})$. When we made calculations for these conditions we found (Appendixes $\mathrm{B}$ and $\mathrm{C}$ ) that a gas phase $\eta$ effect that applied to ozone cannot be invoked to explain the same phenomenon for CAIs: At high temperatures in the low pressure $\mathrm{H}_{2}$-rich environment the "three-body" recombinations, whose analogs 
were responsible for the $\eta$ effect for ozone in gases, cannot compete with two-body reactions such as $\mathrm{O}+\mathrm{H}_{2} \rightarrow \mathrm{OH}+\mathrm{H}$, in determining the steady-state $\mathrm{O}$ atom concentration (Appendix B). Nor can chemiluminescent recombination reactions compete, e.g., the rate of the reaction $\mathrm{O}+\mathrm{CO} \rightarrow \mathrm{CO}_{2}$ $+h \nu$ (Ref. 81) is much less than that of the $\mathrm{O}+\mathrm{H}_{2}$ reaction in competing for the $\mathrm{O}$ atoms (Appendix $\mathrm{B}$ ). Equally importantantly in the early solar system, gas phase dioxides such as $\mathrm{SiO}_{2}$ cannot play the same storage role for ${ }^{17} \mathrm{O}$ and ${ }^{18} \mathrm{O}$ that $\mathrm{O}_{3}$ did in the atmospheric system. They are too unstable in the high temperature $\mathrm{H}_{2}$-rich environment to serve in that capacity (Appendix C and Ref. 82).

Surface recombination on grains instead of in the gas phase has frequently been invoked for chemical reactions at low pressures, notably for $2 \mathrm{H} \rightarrow \mathrm{H}_{2}$ and others. ${ }^{83}$ The many orders of magnitude entropic effect of a surface on the local (surface) position of dioxide/monoxide equilibria is shown in Sec. II B. The entropic effect acts by providing a locally high concentration of species on the surface, in contrast with the dilute concentration in the gas phase, thus shifting the position of an equilibrium of the $A+B \rightleftarrows C$ type to the right. Although the probability of collision of atoms and molecules with the surface to provide this surface concentration is small (estimates are given in Appendix D), such collisions are needed in any case for the growth of a condensed phase, whether it is a solid or a melt. So this way of concentrating atoms and molecules, and so favoring a shift towards $C$ in the recombination of $A$ and $B$, is not an added penalty to the overall condensation process.

Since recombinations in the gas phase are too rare to provide a viable mechanism for the formation of CAI precursor molecules, any invocation of an $\eta$ effect in recombination reactions leading to a CAI must therefore be for reactions occurring on the CAI surface. In this context, we shall see that there is a profound mechanistic difference between the role of the surface in the present case and that found in ozone formation. In the latter, the mass-independent effect disappeared when the recombination occurred on the walls of the reaction vessel, ${ }^{69}$ due to diffusion control or a wall-induced deactivation of the vibrationally excited intermediate.

\section{B. Role of surface in shifting $\mathrm{XO}_{2} / \mathrm{XO}$ and $\mathrm{AIO} / \mathrm{Al}$ equilibria}

We proceed to estimate the entropic surface effect on the reaction $X \mathrm{O}+\mathrm{O} \rightleftarrows X \mathrm{O}_{2}$, where $X$ is $\mathrm{Si}$ or $\mathrm{Al}$, in the case of CAI precursors. Similar remarks apply to $\mathrm{Al}+\mathrm{O} \rightleftarrows \mathrm{AlO}$. The entropic effect on this equilibrium is seen below to be some 12 or so orders of magnitude, though modified by an energy effect.

In the catalytic properties of surfaces one factor is entropic, the ability of these surfaces to bring the reactants to a high local concentration. Their ability to do so depends on forming physical or chemical bonds with the atoms and the molecules. The position of the $A+B \rightleftarrows C$ equilibrium on the surface can be very different from that in the gas phase. For example, at $2000 \mathrm{~K}$, the ratio of $\mathrm{SiO}_{2} / \mathrm{SiO}$ is $3.3 \times 10^{-6}$ in solar gas and the concentration of $\mathrm{O}$ is $\sim 4 \times 10^{8} \mathrm{~cm}^{-3}$. ${ }^{82} \mathrm{We}$ compare this result with the equilibrium on a grain surface.
For concreteness, we suppose that one $\mathrm{O}$ is adsorbed every $10^{4} \AA^{2}$ of grain surface. The local surface $\mathrm{O}$ concentration is then $10^{-4} \AA^{-2}$. Again, apart from energetic concerns, if in a "back of the envelope" estimate the $\mathrm{O}$ is considered to have an order of magnitude amplitude of motion $\sim 1 \AA$ normal to the surface (a large estimate, to be conservative), its local "concentration" becomes $10^{21}$ atoms cm $\mathrm{cm}^{-3}$, an increase of a factor $2.5 \times 10^{12}$. The gas phase value ${ }^{82}$ for $\mathrm{SiO}_{2} / \mathrm{SiO} \sim 2$ $\times 10^{-6}$ is shifted entropically by this large factor. However, an energy term, $\Delta E$ in Eq. (3) below, will reduce this enhancement, since $\mathrm{SiO}$ and $\mathrm{O}$ are expected to be more strongly adsorbed on the surface than $\mathrm{SiO}_{2}$.

A more formal analysis is obtained in a standard way, treating, for simplicity, the motion parallel to the surface as free. We denote $\mathrm{O}, X \mathrm{O}$, and $X_{2}$ by $A, B$, and $C$, respectively, and write the gas phase concentrations in terms of partition functions,

$$
\frac{C}{A \cdot B}=\frac{h^{3}}{(2 \pi \mu k T)^{3 / 2}} \frac{q_{C}}{q_{A B}} e^{-\Delta E / k T},
$$

where $\mu$ is the reduced mass of $X \mathrm{O}$ and $\mathrm{O}$, and $q_{C}$ and $q_{A B}$ are the rotational-vibrational partition functions of the $C$ and the $A B$ pair, respectively, in the gas phase. For species all adsorbed on the surface, we have

$$
\frac{C_{a d s}}{A_{a d s} \cdot B_{a d s}} \cong \frac{h^{2}}{2 \pi \mu k T} \frac{h \nu}{k T} \frac{q_{C}}{q_{A B}} e^{-\Delta E_{a d s} / k T},
$$

where $\nu$ is a typical vibration frequency of the adsorbed species for motion normal to the surface and $\Delta E_{a d s}$ is the dissociation energy for the surface reaction. We take $q_{C}$ and $q_{A B}$ to be roughly the same as in Eq. (1) to obtain a rough estimate. We then find that

$$
\frac{\left(X \mathrm{O}_{2}\right)_{a d s} /(X \mathrm{O})_{a d s}}{X \mathrm{O}_{2} / X \mathrm{O}}=\frac{k T}{\nu} \frac{1}{\sqrt{2 \pi \mu k T}} \frac{\mathrm{O}_{a d s}}{\mathrm{O}} e^{-\left(\Delta E_{a d s}-\Delta E\right) / k T} .
$$

Introducing the cited values of $\mathrm{O}_{a d s}$ and $\mathrm{O}$ and taking $\nu \sim 100$ $\mathrm{cm}^{-1}$ and $\mu$ as the reduced mass for the $(X \mathrm{O}, \mathrm{O})$ pair with $X=\mathrm{Si}$, the preexponential factor in Eq. (3) is $6 \times 10^{11}$. This value is close to the rough estimate of $2.5 \times 10^{12}$ given above. The gas phase $X \mathrm{O}_{2} / X \mathrm{O}$ ratio of $2 \times 10^{-6}$ for $\mathrm{SiO}_{2} / \mathrm{SiO}$ and an approximately similar value for $X=\mathrm{Al}$ show that the $X_{2} \mathrm{O}_{2} / X \mathrm{O}$ ratio is shifted dramatically from its gas phase value, apart from the effect of the surface on the dissociation energy of the reaction, the $\Delta E_{a d s}-\Delta E$ in exponent in Eq. (3). Analogous remarks on enhancement also apply to the AlO/Al ratio. Had a localized site model been used for the adsorbed molecules instead of a mobile phase, the right-hand side of Eq. (2) would have been even larger and the adsorbed ratio larger than that in Eq. (3).

At $1500 \mathrm{~K}$ the $\mathrm{SiO}_{2} / \mathrm{SiO} \mathrm{ratio}^{82}$ is $\sim 6 \times 10^{-7}$, i.e., factor of 3 less than the value at $2000 \mathrm{~K}$. The $\mathrm{O}$ concentration is $\sim 3 \times 10^{3}$ atoms $\mathrm{cm}^{-3}$, about five orders of magnitude less than the value at $1600 \mathrm{~K}$. So now the entropic effect is even larger than at $2000 \mathrm{~K}$, but again is modified by the energy term in Eq. (3). A quasiequilibrium constant given later for reaction (17) will have the same value, regardless of whether the $\mathrm{O}_{a d s}$ is deposited by $\mathrm{O}$ or $\mathrm{H}_{2} \mathrm{O}$. 
Competing Processes on Surface

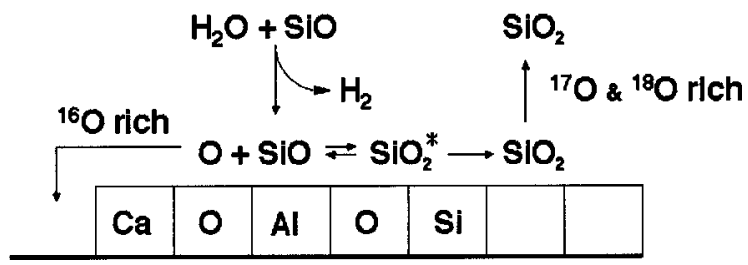

FIG. 1. Schematic diagram of competing processes on the surface of a growing CAI mineral. In more oxidative environments, the initial step could occur as $\mathrm{O}+\mathrm{SiO} \rightarrow \mathrm{O}_{a d s}+\mathrm{SiO}_{a d s}$.

\section{Specific constraints}

We first recall some relevant abundances in CI chondrites, ${ }^{84,85}$ since these abundances and their relevant chemical speciation play a key role in any theory. As an atomic fraction of the $\mathrm{Si}$ abundance, $\mathrm{Al}$ and $\mathrm{Ca}$ are very small, 0.08 and 0.06, respectively, while $\mathrm{O}, \mathrm{C}, \mathrm{Mg}$, and $\mathrm{Fe}$ are $8,0.8,1$, and 0.9 times that of $\mathrm{Si}$, respectively. ${ }^{84,85}$ The CAI minerals form less than $5 \%$ of the total solids in the chondrites. ${ }^{33}$

With the arguments in the preceding section in mind, we consider the following constraints:

(1) We consider CAIs for which the mass-independent phenomenon derives from condensation rather than evaporation. We leave open the question of whether there may also be a similar $\eta$ effect for evaporation.

(2) A surface-adapted $\eta$ effect occurs for the recombination of $\mathrm{O}$ atoms and monoxides on a CAI surface. [The adsorbed oxygen atoms $\mathrm{O}_{a d s}$ can arise from a surface reaction, $\mathrm{H}_{2} \mathrm{O}(g)+$ surface $\rightarrow \mathrm{H}_{2}(g)+\mathrm{O}_{a d s}$-surface, or from gas phase $\mathrm{O}$ atoms. The $\eta$ effect itself is independent of the source of $\mathrm{O}_{a d s}$.]

(3) The CAIs are formed from adsorbed $\mathrm{O}$ atoms and monoxides rather than from adsorbed dioxides and polyoxides. The recombination on the surface to form dioxides in point (2) competes with incorporation of the adsorbed $\mathrm{O}$, monoxides, $\mathrm{Ca}, \mathrm{Al}, \mathrm{Mg}$, and other adsorbed species into the growing $\mathrm{CAI}$.

(4) Dioxide formed by surface recombination in point (2) largely evaporates, as in Fig. 1. In the vapor phase it quickly reacts chemically with $\mathrm{H}$, producing a heavy isotope enriched reservoir.

The mechanism in points (1)-(4) is depicted in Fig. 1. Condition (2) introduces the mass-independent property of $\mathrm{O}$ atom-monoxide recombination in a form where it occurs on the CAI surface. Condition (3) ensures that the $\eta$ effect for CAI formation leads to ${ }^{16} \mathrm{O}$-rich rather than to ${ }^{16} \mathrm{O}$-poor CAIs. A consequence of the $\eta$ effect is to produce a dioxide equally enriched in ${ }^{17} \mathrm{O}$ and ${ }^{18} \mathrm{O} .{ }^{60-64} \mathrm{Point}(4)$ notes the fate of the dioxides after they evaporate. When the dioxides $X_{2}$ and $X \mathrm{O} Q$ formed in reactions (4)-(6) evaporate, as in Fig. 1, they are quickly reduced by $\mathrm{H}$ to form $\mathrm{OH}$ and $Q \mathrm{H}$ (Appendix $\mathrm{C}$ ). This $\mathrm{OH}$ and $Q \mathrm{H}$ then react readily with $\mathrm{H}_{2}$ to form ${ }^{17} \mathrm{O}$ and ${ }^{18} \mathrm{O}$ enriched $\mathrm{H}_{2} \mathrm{O}$ (Appendix E).

There is experimental evidence for condition (3) from studies of the species formed the reverse reaction, ${ }^{86}$ the evaporation of $\mathrm{Mg}_{2} \mathrm{SiO}_{4}$. Using a free evaporation configuration ("Langmuir," nonequilibrium) ${ }^{86}$ it was deduced that the dissociation of $\mathrm{Mg}_{2} \mathrm{SiO}_{4}$ is into $\mathrm{SiO}$ and $\mathrm{O}$, and not directly into $\mathrm{SiO}_{2}$. By condition (3), this mechanism is assumed for the reverse reaction, the condensation.

Isotopic exchange occurs readily in the gas phase between $\mathrm{O}$ atoms and diatomic molecules when there is no energy barrier to forming the triatomic complex. In cases of common interest there is not, e.g., for ozone. ${ }^{60-64}$ This isotopic exchange does not require a "third-body" and does not interfere with mass independence. ${ }^{60}$ In fact, paradoxically perhaps, the isotopic exchange is needed for mass independence (Appendix A and Ref. 60). Isotopic exchange may also occur on the surface, but it certainly occurs in the gas phase.

$\mathrm{H}_{2} \mathrm{O}$ is calculated in Sec. II D to be a more important source of $\mathrm{O}_{a d s}$ than $\mathrm{O}$ under the existing conditions. For the case that $\mathrm{O} \rightarrow \mathrm{O}_{a d s}$ is the preferred source, it would be for minerals formed in some highly oxidative environment. It is reasoned in Appendix D that there is an adequately maintained thermal concentration of gas phase $\mathrm{O}$ atoms at 1500 $2000 \mathrm{~K}$ sufficient to avoid depletion by the formation of the CAIs. Nevertheless, nonthermal sources may provide an enhanced concentration of atoms and radicals as well as raise the temperature of the system.

The ${ }^{17} \mathrm{O}$ and ${ }^{18} \mathrm{O}$ enrichment of $\mathrm{H}_{2} \mathrm{O}$ arising in point (4) has very little initial effect on the isotopic composition of $\mathrm{H}_{2} \mathrm{O}$, since the $\mathrm{O}$ content in CAIs is only a small fraction of that in the total $\mathrm{H}_{2} \mathrm{O}$. However, after a large amount of other minerals has formed this ${ }^{17} \mathrm{O}$ and ${ }^{18} \mathrm{O}$ enrichment has an accumulative effect on the $\mathrm{H}_{2} \mathrm{O}$ isotopic composition.

\section{Kinetic equations}

We denote the monoxides by $X \mathrm{O}$, where $X$ is $\mathrm{Si}, \mathrm{Al}$, and others. $X$ can also be $C$, but the $C$ oxides are too volatile to form CAIs. The rates of the unsuccessful reactions, i.e., those pairs which do not form CAIs but lead to gaseous dioxides that are reconverted to monoxides, are given by reactions (4)-(6):

$$
\begin{aligned}
& X \mathrm{O}_{a d s}+\mathrm{O}_{a d s} \rightarrow \mathrm{O} X \mathrm{O} \quad\left(k_{\mathrm{OO}}^{r}\right), \\
& X \mathrm{O}_{a d s}+Q_{a d s} \rightarrow \mathrm{O} X Q \quad\left(k_{Q}^{r}\right), \\
& X Q_{a d s}+\mathrm{O}_{a d s} \rightarrow Q X \mathrm{O} \quad\left(k_{\mathrm{O}}^{r}\right), \\
& X Q+\mathrm{O} \rightleftarrows X \mathrm{O}+Q \quad(K),
\end{aligned}
$$

where "ads" denotes adsorbed species and the $k^{r}$ s denote recombination rate constants on the surface. $K$ is the equilibrium constant isotopic exchange reaction (7) for the gas phase or adsorbed phase. $Q$ denotes ${ }^{17} \mathrm{O}$ or ${ }^{18} \mathrm{O}$, and the $\eta$ effect is contained in the $k^{r}$ s for reactions (4)-(6), which together with reaction (7) occur via vibrationally excited molecules $X \mathrm{O}_{2}^{*} \cdot{ }^{60-64}$ Their properties lead to the $\eta$ effect (Appendix A).

To derive a theoretical expression for the $k^{r}$ s in Eqs. (4)-(6), we let the rate of formation of $X \mathrm{O}_{2}^{*}$ on the surface in the energy range $(E, E+d E)$ be $k_{f} X \mathrm{O} \cdot \mathrm{O} d E$, where $X$ is $\mathrm{Si}$ in the illustrative example in Fig. 1 and $k_{f}$ depends upon $E$. The rate of the reverse reaction, the dissociation of $X \mathrm{O}_{2}^{*}$ into 
$X \mathrm{O}+\mathrm{O}$, is written as $k_{d} X \mathrm{O}_{2}^{*}$, where $k_{d}$ again depends upon $E$. The rate of vibrational energy loss from $X \mathrm{O}_{2}^{*}$ to the underlying mineral surface, such that the $X_{2}$ can no longer redissociate into $\mathrm{XO}+\mathrm{O}$, is denoted by $k_{c} X \mathrm{O}_{2}^{*}$. This $\mathrm{XO}_{2}$ ultimately evaporates, as in Fig. 1. In a steady-state approximation for $X \mathrm{O}_{2}^{*}$, its concentration is $\left(k_{f} / k_{c}\right) /\left(1+k_{c} / k_{d}\right)$ $\times(d E) X \mathrm{O} \cdot \mathrm{O}$. The $k_{\mathrm{OO}}^{r}$ in Eq. (4) is, after integration over $E$,

$$
k_{\mathrm{OO}}^{r}=\int k_{c}\left(k_{f} / k_{d}\right) /\left(1+k_{c} / k_{d}\right) d E .
$$

This equation is the surface analog of Eq. (1.2) in Ref. 60. However, a fundamental difference in the phenomena to which we alluded earlier is that the successful reactions in the ozone system, successful in that they form ozone, are the unsuccessful reactions here, unsuccessful in that they yield dioxides instead of CAIs. The intramolecular $\eta$ effect affects in the density of states $\rho(E)$ of the vibrationally excited $X \mathrm{O}_{2}^{*}$. The $k_{d}$ in Eq. (8) is inversely proportional to $\rho$ in RRKM (Rice-Ramsperger-Kassel-Marcus) theory and in this $\eta$-modified RRKM theory. So the $\eta$ effect decreases when $k_{c} / k_{d}$ in the denominator in Eq. (8) becomes large, and $k_{d}$ then cancels. (In physical terms, $k^{r}$ no longer depends on $\rho$.) The high thermal energy at $1500-2000 \mathrm{~K}$ enhances $k_{d}$, compared with its value at room temperature, and so this $X \mathrm{O}_{2}^{*}$ molecule is expected to be very short lived. An equation similar to Eq. (8) is obtained for $k_{Q}^{r}$ and another for $k_{\mathrm{O}}^{r}$, when the appropriate $k_{f} \mathrm{~s}$ and $k_{d} \mathrm{~s}$ are introduced. These equations are the analogs of Eq. (1.5) in Ref. 60.

In the case of ozone the enrichment decreases with increasing pressure, ${ }^{67}$ since the dependence of $k^{r}$ on $\rho$ in the equation decreases. However, $k^{r}$ remains mass independent even after it decreases in magnitude by a factor of $10 .{ }^{67}$ The analog in Eq. (8) of this pressure effect is that the enrichment in the evaporated dioxides decreases with increasing $k_{c} / k_{d}$, but continues to be mass independent, even when this quantity becomes large (factor of 10). Eventually this $\eta$ effect becomes comparable in magnitude with ordinary massdependent effects. ${ }^{87}$ Thus, if $\mathrm{SiO}_{2}^{*}$ survives for a number of vibrations before redissociation, a surface based $\eta$ effect becomes possible.

The rate of disappearance of the sum of $\mathrm{O}$ and $X \mathrm{O}$ on the surface by reaction (4) is $2 k_{\mathrm{OO}}^{r} \mathrm{O} \cdot X \mathrm{O}$. The rate of disappearance of the sum of $Q$ and $X Q$ on the surface by reactions (5) and (6) is $\left(k_{Q}^{r}+k_{\mathrm{O}}^{r} K\right) \mathrm{O} \cdot X Q$. The rates of formation of the total $\mathrm{O}$ content and the $Q$ content on the surface before fractionation will be taken as proportional to the total isotopic $\mathrm{O}$ and $Q$ content of the gas, $\mathrm{O}_{\mathrm{T}}$ and $Q_{\mathrm{T}}$, respectively.

For simplicity and notational brevity, we focus on a single $X$. Denoting a proportionality constant by $I$, we have for a steady state of the sums $(\mathrm{O}+X \mathrm{O})$ and $(Q+X Q)$ on the surface, $I \mathrm{O}_{\mathrm{T}}=2 k_{\mathrm{OO}}^{r} \mathrm{O} \cdot X \mathrm{O}$ and $I Q_{\mathrm{T}}=\left(k_{\mathrm{O}}^{r}+k_{Q}^{r} K\right) \mathrm{O} \cdot X Q$. The $K$ in Eq. (7) equals unity to about 1 part per mil at the prevailing temperatures. ${ }^{82}$ We then have

$$
\left(\frac{Q}{Q_{\mathrm{T}}}\right) /\left(\frac{\mathrm{O}}{\mathrm{O}_{\mathrm{T}}}\right)=\frac{1}{R}
$$

where $Q$ and $\mathrm{O}$ refer to the adsorbed species and

$$
R=\frac{k_{\mathrm{O}}^{r}+k_{Q}^{r} K}{2 k_{\mathrm{OO}}^{r}} .
$$

The $K$ is retained in Eq. (10) even though it is in effect unity, to note the similarity to Ref. 60 . In a purely statistical case, it can be shown that $R=1$, and then there is no fractionation in Eq. (9). Since $R$ exceeds 1 , as in Refs. 60-64, the $Q / O$ content on the surface leads to CAIs whose $Q / O$ ratio is less than that in the system as a whole.

We denote the $Q$ and $\mathrm{O}$ content in the CAIs by $Q_{\mathrm{CAI}}$ and $\mathrm{O}_{\mathrm{CAI}}$ and treat their ratio as proportional to the steady-state ratio of $Q$ and $\mathrm{O}$ contents on the surface. This ratio is less than that in the gas phase, when a surface-based $\eta$ effect occurs. The individual "rate constant" for each deposition will depend on the various other concentrations such as $\mathrm{Ca}$ and $\mathrm{Al}$, but cancel in the ratio of rates. The enrichment in $Q$, $\delta Q$, in the condensate can be defined as the ratio of $Q_{\mathrm{CAI}} / Q_{\mathrm{T}}$, divided by $\mathrm{O}_{\mathrm{CAI}} / \mathrm{O}_{\mathrm{T}}$, minus 1 , and multiplied by 1000. We have

$$
\frac{\delta Q}{1000}=\frac{Q_{\mathrm{CAI}} / \mathrm{O}_{\mathrm{CAI}}}{Q_{\mathrm{T}} / \mathrm{O}_{\mathrm{T}}}-1 .
$$

On statistical grounds the $Q_{\mathrm{CAI}} / \mathrm{O}_{\mathrm{CAI}}$ in Eq. (11) is taken to be equal to the total $Q$-containing species adsorbed on the surface divided by the total of the O-containing species on the surface. To apply Eq. (11) we need to take into account that in the mineral the $\mathrm{O}$ typically exceeds the $\mathrm{SiO}$ because of the metallic elements present. So a fraction $w$ of the $\mathrm{O}$ in the adsorbed $\mathrm{O}_{a d s}$ and $\mathrm{SiO}_{a d s}$ undergoes reactions (4)-(6) and so yields an isotopic ratio given by the $1 / R$ in Eq. (9), while a fraction $1-w$ does not and contributes 1 instead of $1 / R . w$ is the $2 \mathrm{SiO} / \mathrm{O}$ ratio in the mineral. The $Q / \mathrm{O}$ content in the mineral relative to that in the entire system is seen to be $(w / R)+1-w$, and Eq. (11) then yields

$$
\frac{\delta Q}{1000}=\left(\frac{1}{R}-1\right) w .
$$

The right-hand side vanishes when $R=1$ or $w=0$, as it should.

The magnitude of $w$ is immediately evident when the mineral contains no $\mathrm{Al}$ : We denote the number of formula units of $\mathrm{SiO}_{2}$ in the mineral by $M$ and the total number of $\mathrm{O}$ atoms by $2 M+N$. From the definition of $w$ we have

$$
w=\frac{2 M}{2 M+N} .
$$

For example, for forsterite, $\mathrm{Mg}_{2} \mathrm{SiO}_{4}, M=1, N=2$, and so $w=1 / 2$.

To include $\mathrm{Al}_{2} \mathrm{O}_{3}$-bearing minerals, we use the following argument based on an interpretation of solid solutions. The formula unit $\mathrm{Al}_{2} \mathrm{O}_{3}$ replaces groups such as $\mathrm{MgSiO}_{3}$, $\mathrm{CaSiO}_{3}$, and $\mathrm{FeSiO}_{3}$ in a solid solution. On this basis, each $\mathrm{Al}_{2} \mathrm{O}_{3}$ is equivalent to one $\mathrm{SiO}_{2}$ and one additional $\mathrm{O}$, i.e., it is assumed to contribute 1 to the value of $M$ and 1 to the value of $N$. Accordingly, for spinel, $\mathrm{MgAl}_{2} \mathrm{O}_{4}$, we have $M$ $=1, N=2$, and so $w=1 / 2$. For hibonite, $\mathrm{MgAl}_{12} \mathrm{O}_{19}$, we have $M=6, N=7$, and so $w=12 / 19$. For forsterite, $\mathrm{Mg}_{2} \mathrm{SiO}_{4}$, as noted above, $M=1, N=2$, and so $w=1 / 2$; me- 
lilite, $\mathrm{Ca}_{2} \mathrm{Mg}_{x} \mathrm{Si}_{1+x} \mathrm{Al}_{2-2 x} \mathrm{O}_{7}$, has $M=2, N=3$, and so $w$ $=4 / 7$; and pyroxene, $\mathrm{Ca}_{y} \mathrm{Mg}_{x-y} \mathrm{Fe}_{1-x} \mathrm{SiO}_{3}$, has $M=1, N$ $=1$, and so $w=2 / 3$. The $w$ 's in these examples vary from $1 / 2$ to $2 / 3$, which is not a very large variation.

Although $\mathrm{AlO}_{2}$ and $\mathrm{SiO}_{2}$ have very different stabilities with respect to complete dissociation into atoms, their dissociation energies to the monoxides $\mathrm{AlO}_{2} \rightarrow \mathrm{AlO}+\mathrm{O}$ and $\mathrm{SiO}_{2} \rightarrow \mathrm{SiO}+\mathrm{O}$ are calculated to be essentially the same. ${ }^{82}$ The calculated vibration frequencies of the two molecules are not very different from each other, ${ }^{82}$ those of $\mathrm{AlO}_{2}$ being smaller. Accordingly, if the surface-based $\eta$ effect exists, it may be somewhat similar for the surface-adsorbed $\mathrm{AlO}_{2}$ and $\mathrm{SiO}_{2}$ species.

The CAI formation is a small conversion (a few percent or less) of the total material and its rate of formation is estimated in Appendix D to be small compared with the rates of any competing gas phase reactions which determine the steady-state $\mathrm{O}$ and $Q$ concentrations in the gas phase. Thus, we do not need to take into account the changing gas phase concentrations.

When several minerals are codepositing a detailed mechanistic description of the condensation is ultimately needed for any analysis, but, the main direction is clear, a mass-independent equation is obtained with the deposited minerals being richer in ${ }^{16} \mathrm{O}$ when a surface-based $\eta$ effect exists.

\section{E. Kinetics of condensation and evaporation}

The rate of growth of simple and multicomponent crystals from solution is frequently expressed as a function of $(S-1)$, where $S$ is the supersaturation. ${ }^{88-91}$ The behavior is often interpreted in terms of the spiral dislocation theory of crystal growth. ${ }^{91}$ However, the concentrations used in such studies are usually stochiometric. More generally, the rate depends also on ionic ratios. ${ }^{92}$ We use instead a different analysis in the literature, typically applied to evaporation of solids (Ref. 93 and references cited therein), but also applicable to condensation of vapors [it is designated as HKS (Hertz-Knudsen-stoichiometric fluxes) below]. While it is less mechanistic, in that it introduces a parameter $\alpha$, it has the merit of introducing in a simple way the correct ratios of the fluxes of the depositing species. The two approaches have the same dependence on concentrations only in the linear $(S-1)$ regime and then only when the concentrations are proportional to their equilibrium values. (In most solution crystallization experiments the rate is quadratic in $S-1$, the extra factor being due to the dependence of a "kink" density on $S-1$ in spiral growth theory when $S-1$ is small. ${ }^{88-91}$ )

We consider next some results obtained for vapor-solid equilibria. Here, unlike crystallization from solution there are no or almost no experimental studies of the kinetics of condensation. The study of the reverse process of evaporation has been extensive, particularly for $\mathrm{Mg}_{2} \mathrm{SiO}_{4}$, but the concentrations of the congruently evaporating species have usually been fixed by the stoichiometry of the mineral. In detailed condensation studies, in contrast, the concentrations of the condensing species could be varied independently. In the absence of such information we focus on results available from evaporation. We utilize studies of evaporation of $\mathrm{Mg}_{2} \mathrm{SiO}_{4}$ (Ref. 93 and references cited therein). The rate of evaporation of various magnesium minerals ${ }^{94}$ has been studied in the presence of the different partial pressures of a product, oxygen that reduces the rate of the evaporation. The results are discussed elsewhere using the HKS formalism. ${ }^{95}$

In the reactions before and following the evaporation of the dioxides in Fig. 1, there is a rapid equilibration of oxygen isotopes and a chemical equilibrium among the species $\mathrm{OH}$, $\mathrm{H}_{2} \mathrm{O}, \mathrm{O}, \mathrm{SiO}$, and $\mathrm{CO}$ : For example, from data on rate constants and estimated ${ }^{82}$ concentrations in the solar gas the lifetimes of $\mathrm{OH}$ reacting with $\mathrm{H}_{2}$, of $\mathrm{OH}$ reacting with $\mathrm{H}$, and of $\mathrm{SiO}_{2}$ reacting with $\mathrm{H}$ are very short (Appendixes $\mathrm{C}$ and $\mathrm{E}$ ). These two-body gas phase reactions provide thereby a rapid gas phase equilibration of their species at 1500-2000 K.

We first consider chemical steps for a condensation using $\mathrm{Mg}_{2} \mathrm{SiO}_{4}$ purely as an illustration, irrespective of any isotope effect:

$$
\begin{aligned}
& \mathrm{SiO}(g) \rightleftarrows \mathrm{SiO}_{a d s}, \\
& \mathrm{Mg}(g) \rightleftarrows \mathrm{Mg}_{a d s}, \\
& \mathrm{H}_{2} \mathrm{O}(g) \rightleftarrows \mathrm{O}_{a d s}+\mathrm{H}_{2}(g)
\end{aligned}
$$

or

$$
\begin{aligned}
& \mathrm{O}(g) \rightleftarrows \mathrm{O}_{a d s}, \\
& \mathrm{O}_{a d s}+\mathrm{SiO}_{a d s} \rightleftarrows \mathrm{SiO}_{2 a d s}, \\
& \mathrm{SiO}_{2 a d s} \rightarrow \mathrm{SiO}_{2}(g),
\end{aligned}
$$

followed by reactions of $\mathrm{Mg}_{a d s}, \mathrm{SiO}_{a d s}$, and $\mathrm{O}_{a d s}$ to form $\mathrm{Mg}_{2} \mathrm{SiO}_{4}$.

In the HKS method a Hertz-Knudsen-based expression $^{96-98}$ for the flux density $J_{i}$ is introduced for each species $i$ :

$$
J_{i}=\alpha_{i} \sqrt{k T / 2 \pi m_{i}}\left(c_{i}-c_{i}^{e}\right),
$$

where $\alpha_{i}, m_{i}, c_{i}$, and $c_{i}^{e}$ are the collision sticking probability, the mass, the concentration, and the equilibrium concentration of the $i$ th species, respectively. To achieve the desired stoichiometry of the condensed phase, the ratios of fluxes, $J_{i} / J_{j}$, are set equal to the ratio of stoichiometric numbers of the species in the mineral, $\nu_{i} / \nu_{j}$. Since the product of the equililbrium concentrations $\Pi_{i}\left(c_{i}^{e}\right)^{\nu_{i}}$ is known from thermodynamics to be a constant, these equations can be solved for the individual $c_{i}^{e}$ 's as a function of all $c_{j}$ 's. As an approximation, the individual $\alpha_{i}$ 's are set equal to a constant $\alpha$, where by experiment $\alpha \sim 0.1$ (Ref. 93 and references cited therein). For evaporation a "microscopic reversibility" is introduced but the resulting factor $\alpha$ for evaporation may differ from the $\alpha$ for condensation, except at equilibrium. The $\alpha$ for condensation of a purely monatomic species is about 1.0. ${ }^{96}$ The $\alpha$ for evaporation of forsterite is temperature dependent and varying between 0.04 and 0.17 in the presence and absence of $\mathrm{H}_{2}$ (data are summarized in Ref. 99). A value of $\alpha$ for condensation of forsterite has also been obtained and is approximately equal to that for evaporation. ${ }^{100}$

This evaporation of $\mathrm{Mg}_{2} \mathrm{SiO}_{4}$ in the presence of $\mathrm{H}_{2}$ involves the inverse of the two reactions in Eq. (16), and we infer from Ref. 99 that $\alpha$ is more or less similar for these two 
reactions. We can then use the HKS formalism, together with the data in Ref. 93, to conclude that $\mathrm{H}_{2} \mathrm{O}$ is favored over $\mathrm{O}$ in Eq. (16) as the dominant reactant in the condensation. This result is due to the ratio of the gas phase concentrations $\mathrm{H}_{2} \mathrm{O} / \mathrm{O}$ being very large, ${ }^{101} \sim 1.5 \times 10^{3}$ at $2000 \mathrm{~K}$ and much larger at $1500 \mathrm{~K}$.

The equilibrium condensation temperature for $\mathrm{Mg}_{2} \mathrm{SiO}_{4}$ has been calculated to occur somewhat below $1500 \mathrm{~K},{ }^{47}$ though the kinetic factor will raise that value. The latter has been suggested ${ }^{102}$ as a possible reason for $\mathrm{Mg}_{2} \mathrm{SiO}_{4}$ being more refractory than expected from equilibrium calculations. Dust enrichment also raises the condensation temperature. ${ }^{44}$

In the case of $\mathrm{Ca}$ and $\mathrm{Al}$ minerals, the $\mathrm{Ca}$ and $\mathrm{Al}$ concentrations are the smallest ones in the condensing species and in a HKS analysis will typically be rate controlling, i.e., the rate will be proportional to $\left(\mathrm{Ca}-\mathrm{Ca}^{e}\right)$, where $\mathrm{Ca}^{e}$ is the equilibrium concentration determined from the HKS formalism. ${ }^{95}$

\section{DISCUSSION}

The slope of a three-isotope enrichment plot of ${ }^{17} \mathrm{O} /{ }^{16} \mathrm{O}$ versus ${ }^{18} \mathrm{O} /{ }^{16} \mathrm{O}$ need not be exactly 1.0 to be described as mass independent. For example, in the case of ozone the enrichments of the many isotopologus for heavily ${ }^{17} \mathrm{O}$ and ${ }^{18} \mathrm{O}$ enriched systems are not exactly equal, either experimentally ${ }^{73}$ or theoretically. ${ }^{62,63}$ There are very small mass-dependent contributions. ${ }^{87}$ However, on theoretical grounds such differences are expected to disappear at high temperatures, thus making the plot of $\delta^{17} \mathrm{O}$ versus $\delta^{18} \mathrm{O}$ for CAIs formed at high temperatures have a slope close to 1.0. For the CAIs from the Allende meteorite, the slope of the line is $0.94 \pm 0.02 .{ }^{21}$ However, it has been argued that when corrected for some subsequent processing, the slope is 1.0. ${ }^{12}$

Other reactions also show interesting isotopic mass anomalies. The reaction $\mathrm{CO}+\mathrm{OH} \rightarrow \mathrm{CO}_{2}+\mathrm{H}$ has a $\Delta^{17} \mathrm{O}$, defined as $\delta^{18} \mathrm{O}-0.52 \delta^{17} \mathrm{O}$, which differs from the massdependent value of zero and so is anomalous. ${ }^{101,103,104}$ Data ${ }^{101,103}$ for a plot of $\delta^{18} \mathrm{O}$ versus $\delta^{17} \mathrm{O}$ are presently too few to determine the slope unequivocally, but a preliminary value is about $0.7-0.75 .^{82}$ There is some reason, therefore, to suspect that it may not produce the desired slope of 1.0, or very close to 1.0, found for the CAIs. Again, a mass anomaly in the $\mathrm{O}$ isotopic composition in $\mathrm{CO}$ in the atmosphere has been attributed to the $\mathrm{CO}+\mathrm{OH}$ reaction and the data show a slope less than $0.52{ }^{105}$ Indeed, unlike the phenomenon in ozone, no theoretical argument has been offered thus far to suggest that this reaction should show a slope of unity. At the moment, therefore, if there is a chemical origin for the massindependent isotope phenomenon in CAIs, we appear to be left with an origin based on the $\eta$ effect in transient surface recombination.

Any quantitative theory for the $\eta$ effect will involve detailed quantum mechanical calculations on the formation, lifetime, and disappearance of vibrationally excited chemical intermediates. Such calculations are computationally intensive and are now being undertaken for ozone. ${ }^{106,107}$ The results will be extremely interesting. It will be an added challenge to calculate $\delta Q$, since it is a small difference between four large quantities. ${ }^{60}$
When the $\eta$ effect is intramolecular based (the first origin listed in Appendix A) one expects that the magnitude of $\eta$ will depend on the density of states, $\rho$, of the vibrationally excited molecule: When the states are sparse, i.e., when $\rho$ is small, there will be less efficient intramolecular energy transfer and so less "statistical" behavior. Intramolecular energy transfer occurs by internal resonances among the various coordinates, and the probability of these resonances existing is smaller when $\rho$ is smaller.

Ozone has a relatively low dissociation energy of about $1.1 \mathrm{eV}$, and so $\rho$ is comparatively small. The dissociation energies of $\mathrm{SiO}_{2}$ and $\mathrm{AlO}_{2}$ are larger. As a result, they have a higher $\rho$, and so may be less apt to show nonstatistical behavior. On the other hand, in the limited data available covering a $200 \mathrm{~K}$ range in temperature, the $\eta$ for ozone increased with increasing temperature. ${ }^{70}$ This effect can be understood or rationalized in terms of either mechanism and is related to a shorter time for energy redistribution or for collisional deactivation energy transfer at the prevailing pressure when the temperature is increased. Thus, the $\eta$ effect may be larger at the high temperatures of 1500-2000 K.

To obtain a $\delta Q$ of -40 per mil in the present case, using a typical $w$ of $1 / 2$ in Eq. (12), an $R$ of about 1.08 is needed. In the present case a $\delta Q$ of 1.04 corresponds to an $R$ of 1.08 and to an $\eta$ of 1.08. In the case of ozone, $\eta$ was about 1.15 and corresponded to an $R$ of about $1.10 .{ }^{108}$ There is no reason why the two $\eta$ 's, obtained at very different temperatures and for very different molecules, should be the same, but a lower $\eta$ for the CAIs can arise from the deactivation in Eq. (8). In the case of ozone the enrichment is temperature dependent. It increases with increasing temperature, ${ }^{70}$ and hence $\eta$ also does.

The magnitude of $R$ at $1500-2000 \mathrm{~K}$ in Eq. (10) has not been experimentally measured for the CAIs, or for any reaction, gas or surface-based, at those temperatures. Experiments on the isotope effect on the gas recombination phase reaction $\mathrm{O}+X \mathrm{O}+M \rightarrow X \mathrm{O}_{2}+M$ at low pressures ( $M$ is a third body) and high temperatures, with $X=\mathrm{C}$ or $\mathrm{Si}$, would be useful to see if a nonzero $\eta$ effect occurs under those conditions. The reaction $\mathrm{O}+\mathrm{CO}+M \rightarrow \mathrm{CO}_{2}+M$ has been shown to have an anomalous isotope effect at room temperature. ${ }^{105}$ It would be interesting to study this reaction at $1500-2000 \mathrm{~K}$, perhaps using $\mathrm{N}_{2} \mathrm{O}$ photolysis as a source of $\mathrm{O}$. (Use of $\mathrm{O}_{2}$ photolysis has added complications, due to the transient $\mathrm{O}_{3}$ formed. Use of $\mathrm{N}_{2} \mathrm{O}$ is also complicated since it yields $\mathrm{O}\left({ }^{1} \mathrm{D}\right)$ atoms, depending upon the wavelength.) The $\mathrm{O}+\mathrm{CO}$ reaction can have an anomalous ${ }^{18} \mathrm{O}$ effect, due to an $\eta$ effect. A twofold effect may occur for ${ }^{17} \mathrm{O}$, due to an $\eta$ effect and a possible hyperfine spin-spin interaction, since ${ }^{17} \mathrm{O}$ has a nuclear spin and so the spinforbidden nature of the reaction may be less (Appendix F).

The more difficult study of the existence of an $\eta$ effect on a solid phase (or melt) would be particularly desirable, using a source of $\mathrm{SiO}$ and of $\mathrm{H}_{2} \mathrm{O}$ (or $\mathrm{O}$ ), and other atoms such as $\mathrm{Ca}$ or $\mathrm{Al}$. The latter would also provide nearby electron spins which would reduce the spin-forbidden nature of reaction (1) (Appendix F). The conditions need to be such as to favor an $X \mathrm{O}_{a d s}+\mathrm{O}_{a d s} \rightleftarrows X \mathrm{O}_{2 a d s}^{*}$ equilibrium on the surface, with the removal of the deactivated ${ }^{17} \mathrm{O}$ - and ${ }^{18} \mathrm{O}$-rich 
$X \mathrm{O}_{2}$, as in Fig. 1, instead of its remaining permanently on the surface.

This removal of the ${ }^{17} \mathrm{O}$ - and ${ }^{18} \mathrm{O}$-rich $\mathrm{SiO}_{2}$ from the surface of the growing CAI may be by evaporation, as in Fig. 1 , or by reaction with $\mathrm{H}$. In this view a reducing atmosphere, perhaps similar to that in solar gas, may be helpful. Whether well-defined crystallization processes (e.g., methods of vapor phase crystal growth discussed in Refs. 109 and 110) are needed is not clear. However, an interesting result has been obtained, in which a "smoke" of composition $\mathrm{SiO}_{1.5}-\mathrm{SiO}_{1.8}$ was produced from silanes, oxygen, and hydrogen in a condensation flow apparatus. ${ }^{79}$ Two of the three experiments yielded mass-dependent results for a $\delta^{17} \mathrm{O}$ versus $\delta^{18} \mathrm{O}$. However, one experiment which was abbreviated abruptly by an explosion ${ }^{111}$ gave anomalous isotopic results, the solids being richer in ${ }^{16} \mathrm{O}$ than in the starting material and with an anomalous slope of 0.72 for the $\delta^{17} \mathrm{O}$ versus $\delta^{18} \mathrm{O}$ plot.

Whether or not the shorter available time for isotopic equilibration was a factor or whether at the relatively low temperature $(800 \mathrm{~K})$ and in an environment relatively oxidizing compared with solar gas the observed effect was volume based rather than surface-based remains to be investigated. The absence of an extra enhancement of $\delta^{17} \mathrm{O}$ due to hyperfine interaction (Appendix F) in this metal atom-free (but not spin free) system is of interest. While the ground state of $\mathrm{O}$ is a triplet, and so reactions (4)-(6) are spin forbidden when they occur in the gas phase, the spin state of $\mathrm{O}_{a d s}$ remains to be clarified.

To form ferromagnesian silicates with an artificially high ${ }^{16} \mathrm{O}$ content in this type of laboratory experiment, even though they are not normally so ${ }^{16} \mathrm{O}$ rich, the starting laboratory material could contain $\mathrm{Fe}$ and $\mathrm{Mg}$ in small amounts relative to the silica together with a quantity of more volatile metals, and no $\mathrm{Ca}$ and $\mathrm{Al}$. Use of the same conditions as for the CAIs, but at a lower temperature to permit deposition, will lead to heavily ${ }^{16} \mathrm{O}$ enriched ferromagnesian silicates, if the present surface-based mechanism is applicable. The enrichment would be mass independent.

\section{ACKNOWLEDGMENTS}

It is a pleasure to acknowledge the support of this research by the National Science Foundation. The many interactions with Wei-Chen Chen have been invaluable. I am pleased to acknowledge earlier discussions with my other co-workers, Dr. Y. Q. Gao and Dr. J. Weibel. It is particularly a pleasure, too, to acknowledge helpful discussions and correspondence with many colleagues-Dr. C. Alexander, Dr. R. Clayton, Dr. J. R. Lyons, Dr. K. D. McKeegan, Dr. A. Pack, Dr. H. Palme, Dr. M. H. Thiemens, Dr. E. D. Young, and Dr. G. J. Wasserburg. I am pleased to acknowledge the many discussions with members of the Institute of Geophysical and Planetary Physics at UCLA while I was a guest and Slichter Lecturer at that Institute.

\section{APPENDIX A: NATURE OF THE $\eta$ EFFECT}

We briefly summarize here the nature of the $\eta$ effect. There are two possible origins, intramolecular and intermolecular. ${ }^{63}$ We consider the intramolecular origin first.
If $Q$ denotes ${ }^{17} \mathrm{O}$ or ${ }^{18} \mathrm{O}$, in an intramolecular $\eta$ effect the vibrationally excited asymmetric molecule $\mathrm{OX} Q^{*}$ formed from $\mathrm{O} X+Q$ or $\mathrm{O}+Q X$ has more mixing of vibrational energy among its various vibrational modes than has a symmetric molecule $\mathrm{OXO}^{*}$ formed from $\mathrm{O}+X \mathrm{O}$ : There is more mixing because some of the Hamiltonian terms (the dynamical matrix elements responsible for the mixing) are forbidden by symmetry in $\mathrm{OXO}^{*}$, but not in $\mathrm{OX} Q^{*}$. The poorer mixing yields a less statistical behavior and, thereby, a smaller effective density of quantum states of the vibrationally excited molecule and, in RRKM-type theory, a longer lifetime for dissociation. Its longer life makes it more likely to be deactivated by collision to form $\mathrm{O} X Q$ than does $\mathrm{O} X \mathrm{O}$, and so yields a higher recombination rate constant. This recombination rate constant is mass independent since the asymmetry property and its consequence noted above are independent of whether $Q$ is ${ }^{17} \mathrm{O}$ or ${ }^{18} \mathrm{O} .{ }^{60-64}$ Similarly, starting instead from the dioxide, one can show that the thermal dissociation rate constant for $\mathrm{OXQ}$ is mass independently greater than that for a symmetric molecule $\mathrm{OXO}$. There are small mass-dependent terms, whose calculated small magnitude can be seen rather dramatically in Fig. 7 of Ref. 63, where the small boxes represent the size of the massdependent effects.

An alternative possible origin of the $\eta$ effect is an intermolecular one. The density of states in $\mathrm{OO} Q^{*}$ is twice as large as that in $\mathrm{OQO}^{*}$ or $\mathrm{O}_{3}^{*}$ and so it has a better chance for collisional energy transfer in the deactivation to form $\mathrm{OO} Q$ or $\mathrm{O}_{3}$. There is also a rotational asymmetry in the interaction potential for $\mathrm{OO} Q^{*}$, but it would be larger for ${ }^{18} \mathrm{O}$ than for ${ }^{17} \mathrm{O}$ and arises from the rotational asymmetry of $\mathrm{O} X Q$ affecting its collisional deactivational energy transfer, as discussed in Ref. 63.

A theoretical expression incorporating the $\eta$ effect for ozone $^{60}$ is simple looking. It is the analog of Eqs. (9) and (10) and is valid only when there is extensive isotopic exchange. Not realizing this major theoretical proviso, some ozone data have been corrected for isotopic exchange. ${ }^{58,70}$ It should be stressed that it is only the uncorrected data for which current theory yields mass independence, ${ }^{60}$ not the corrected data. Indeed, the key role played by isotopic exchange in achieving the phenomenon of mass independence is evident: when isotopic exchange is deliberately inhibited, strikingly large $\mathrm{O}$ isotopic mass effects occur ${ }^{66-69}$ and they are decidedly not mass independent. In the theoretical expression for the enrichment given in Ref. 60 there is an exact cancellation of a mass dependence of the individual rate constants. The cancellation results from a sum of partitioning factors in Ref. 60 being unity when isotopic exchange between atoms and diatomics is complete. It is the partitioning factors that account for individual rate constant ratios having a marked mass dependence observed experimentally. These partitioning factors differ from a statistical value of $1 / 2$ only because of differences in the zero-point energies in the two exit channels of a dissociating $\mathrm{OO} Q^{*}$ molecule, $\mathrm{OO} Q^{*}$ $\rightarrow \mathrm{OO}+Q$ and $\mathrm{OO} Q^{*} \rightarrow \mathrm{O}+\mathrm{O} Q$.

It has been proposed ${ }^{70}$ that the temperature effect in the mass-independent enrichment in ozone has its origin in the $\mathrm{OO} Q^{*}$ 's whose energy is low enough that the differences in 
zero-point energies of the two exit channels are important. However, as noted above, in the framework of the theory in Refs. 60-64, the effect of a zero-point energy difference cancels exactly when there is extensive isotopic exchange. So the temperature effect on enrichment has a quite different origin, perhaps the one suggested above.

An interesting feature of the theory and of the two different types of experiments that have been understaken for ozone formation is that one type (labeled "scrambled" ${ }^{\prime 60}$ ) exhibits mass independence and is independent of the zeropoint energy difference effect. It depends only on the $\eta$ effect. The other type (labeled "unscrambled" ${ }^{60}$ ) involves ratios of rate constants and is much less sensitive to $\eta$. It depends, instead, primarily on the difference in zero-point energies of the two exit channels. It is dependent on the latter because of their effect on the "partitioning factors." The energy range for the relevant partitioning factors, in turn, depends on a collisional energy transfer term, $\Delta E .{ }^{62-64}$ Thus, $\eta$ affects the scrambled enrichments experiment while $\Delta E$ is the dominant factor affecting the individual mass-sensitive ratios of recombination rate constants.

The isotopic exchange also serves to erase any isotopic fractionation resulting from the primary photochemical act, which creates the $\mathrm{O}$ atoms that later combine with the $\mathrm{O}_{2}$ to form $\mathrm{O}_{3}$. Such fractionation would occur unless the light source is broad enough to encompass the entire absorption band, or happens to occur at the maximum of the absorption band. At wavelengths away from the maximum there are many examples of photolytic fractionation for spin-allowed systems, such as, Ref. 112. When the photolysis is spin forbidden (Appendix F) fractionation occurs at every wavelength.

\section{APPENDIX B: RATES OF O+ $\mathrm{H}_{2} \rightarrow \mathrm{OH}+\mathrm{H}$ AND $\mathrm{O}+\mathrm{CO}+\mathrm{M} \rightarrow \mathrm{CO}_{2}+\mathrm{M}$}

At $2000 \mathrm{~K}$, the $\mathrm{O}+\mathrm{H}_{2}$ reaction has a rate constant available in standard NIST tables ${ }^{113}$ of about $10^{-11} \mathrm{~cm}^{3}$ molecule $\mathrm{s}^{-1}$, and the recombination reaction $\mathrm{O}+\mathrm{CO}+M \rightarrow \mathrm{CO}_{2}+M$, where $M$ is a third body, has a rate constant of about $10^{-33} \mathrm{~cm}^{6}$ molecule $\mathrm{s}^{-2} \mathrm{~s}^{-1}$. At a pressure of $0.001 \mathrm{bar}$, its effective bimolecular rate constant is then about $4 \times 10^{-18} \mathrm{~cm}^{3}$ molecule ${ }^{-1} \mathrm{~s}^{-1}$. The ratio of $\mathrm{H}_{2} / \mathrm{CO}$ in the solar gas is about $10^{3}$. Thus, the ratio of the rate of the $\mathrm{O}+\mathrm{H}_{2} \rightarrow \mathrm{OH}+\mathrm{H}$ reaction to that of $\mathrm{O}+\mathrm{CO}+M \rightarrow \mathrm{CO}_{2}+M$ is about $2.5 \times 10^{9}$. The ratio of the $\mathrm{O}+\mathrm{H}_{2} \rightarrow \mathrm{OH}+\mathrm{H}$ reaction rate to that of $\mathrm{O}+\mathrm{SiO}+M \rightarrow \mathrm{SiO}_{2}+M$ would be expected to be roughly similar. The lifetime of an $\mathrm{O}$ reacting with $\mathrm{H}_{2}$ is estimated from the rate constant and $\mathrm{H}_{2}$ concentration in solar gas to be about $25 \mu \mathrm{s}$. If the system were dust enriched by a factor of $10^{3}$, resulting in a smaller reduced $\mathrm{H}_{2}$ concentration at the given total pressure, the ratio of rates of reaction of $\mathrm{O}$ with $\mathrm{H}_{2}$ to that with $\mathrm{CO}$ would be reduced to 2.5 $\times 10^{6}$, which is still extremely large. Thus, the disappearance of $\mathrm{O}$ by three-body recombination is minor under such conditions. The system clearly differs in a major way from the ozone system.

At $1500 \mathrm{~K}$, the $\mathrm{O}+\mathrm{CO}+M \rightarrow \mathrm{CO}_{2}+M$ reaction has an effective bimolecular rate constant of $3 \times 10^{-8}$ $\mathrm{cm}^{3}$ molecule ${ }^{-1} \mathrm{~s}^{-1}$ at 0.001 bar. ${ }^{113}$ The $\mathrm{O}+\mathrm{H}_{2} \rightarrow \mathrm{OH}+\mathrm{H}$ rate constant is ${ }^{113} 2.5 \times 10^{-12} \mathrm{~cm}^{3}$ molecule $\mathrm{s}^{-1} \mathrm{~s}^{-1}$. With a $\mathrm{H}_{2} / \mathrm{CO}$ ratio of 1000 , the $\mathrm{H}_{2}$ reaction is faster than CO reaction by a factor of $10^{6}$.

\section{APPENDIX C: RATE OF $\mathrm{H}+X_{2} \rightarrow \mathrm{HO}+X \mathrm{O}, X=\mathrm{C}, \mathrm{Si}$}

At $2000 \mathrm{~K}$ and $0.001 \mathrm{bar}$, the rate constant for the reaction $\mathrm{H}+\mathrm{XO}_{2} \rightarrow \mathrm{HO}+X \mathrm{O}$, obtained from standard NIST tables $^{113}$ for the given conditions, is $3 \times 10^{-13} \mathrm{~cm}^{3}$ molecule $\mathrm{e}^{-1} \mathrm{~s}^{-1}$ for $X=\mathrm{C}$. Using these tables for the reverse reaction for $X=\mathrm{Si}$ and the Janaf Thermodynamic tables, ${ }^{82}$ the rate constant for $X=\mathrm{Si}$ is $3 \times 10^{-11} \mathrm{~cm}^{3}$ molecule $\mathrm{s}^{-1} \mathrm{~s}^{-1}$. For a concentration of $\mathrm{H}$, for the cited conditions, of $\sim 2$ $\times 10^{14}$ molecule $\mathrm{cm}^{-3},{ }^{85}$ the lifetime of a $\mathrm{CO}_{2}$ molecule is $\sim 15 \mathrm{~ms}$ and that of a $\mathrm{SiO}_{2}$ is $\sim 150 \mu \mathrm{s}$. At $1500 \mathrm{~K}$, the lifetimes are estimated to be longer by a factor of the order of 10 .

\section{APPENDIX D: GROWTH RATES AND COMPETITION WITH OTHER SOURCE OF O-ATOM REMOVAL}

For concreteness, we consider a stage of growth where $1 \%$ of the silicon species is present as grains of radius $\sim 100$ $\AA$, a radius taken from an interstellar grain size. ${ }^{114} \mathrm{We}$ also consider a radius $\sim 1000 \AA$. Using forsterite, $\mathrm{Mg}_{2} \mathrm{SiO}_{4}$, as an example, with its known specific gravity, and using the solar elemental abundance, ${ }^{84,85}$ there are calculated to be about $4 \times 10^{6}$ grains $\mathrm{cm}^{-3}$ at the temperature and pressure used here. We use the Knudsen-Hertz formula ${ }^{96-98}$ for the rate of condensation on the surface of a grain, $\alpha A c \sqrt{ }(k T / 2 \pi m)$, with terms defined in the text and with $A$ being the area of the grain. Taking $\alpha$ to be $\sim 0.1$ (Ref. 93) and using the solar gas concentration of $\mathrm{O}$ of $\sim 2 \times 10^{8} \mathrm{~cm}^{-3}$ under the cited conditions, ${ }^{82}$ the first-order rate of loss of $\mathrm{O}$ onto one grain is calculated to be $\sim 75 \mathrm{~s}^{-1}$.

With the above estimate of the grain density, the rate of loss of $\mathrm{O}$ on the grains is $3 \times 10^{8}$ atoms $\mathrm{cm}^{-3} \mathrm{~s}^{-1}$. This quantity is small compared with the rate of loss of $\mathrm{O}$ by the reaction $\mathrm{O}+\mathrm{H}_{2} \rightarrow \mathrm{OH}+\mathrm{H}$ of $\sim 10^{13}$ atom $\mathrm{cm}^{-3} \mathrm{~s}^{-1}$. So the deposition is indeed a small perturbation of the steady-state O concentration, as would be needed for Eqs. (9) and (10) had $\mathrm{O}$ been the dominant reactant in reaction (16) rather than $\mathrm{H}_{2} \mathrm{O}$. For this size grains and pressures, it is also readily shown, by many orders of magnitude, that diffusion in the gas phase to a grain is not the slow step. In the case of $\mathrm{H}_{2} \mathrm{O}$ instead of $\mathrm{O}$ in reaction (16) yielding $\mathrm{O}_{a d s}$, the question of depletion of a steady-state $\mathrm{O}$ concentration does not arise.

To consume as much as $\sim 5 \%$ of the Si species by forming minerals at the above condensation rate and noting that one $\mathrm{SiO}$ disappears for every $2 \mathrm{O}$ atoms, the rate of loss of the $\mathrm{SiO}$ is twice as great as that of the $\mathrm{O}$ atoms, and so is of the order of $1.5 \times 10^{8}$ molecule $\mathrm{cm}^{-3}$. Since there are $\sim 3$ $\times 10^{11} \mathrm{SiO} \mathrm{cm}^{-3}$ initially, one would require a time $\sim 3$ $\times 10^{11} /(20)(1.5) \times 10^{8}$, i.e., $\sim 10^{2} \mathrm{~s}$, a very short time. As the particles grow, the surface/volume ratio decreases, and the rate of deposition of $\mathrm{SiO}$ becomes slower, but not dramatically. We also see that there is no need to postulate a photochemical source of $\mathrm{O}$ to reduce the time of the $\mathrm{O}$ deposition. At $1500 \mathrm{~K}$, the $\mathrm{AlO}$ and $\mathrm{SiO}$ concentrations are about the same as at $2000 \mathrm{~K}$, but the $\mathrm{O}$ concentration is about a 
factor of $2.5 \times 10^{4}$ less, so there is lengthening of time for $5 \%$ deposition of $\mathrm{O}$ to $\sim 2.5 \times 10^{6} \mathrm{~s}$, which is still a very short time.

The $\mathrm{O}$ atom concentration was estimated as $\sim 2 \times 10^{8}$ atom $\mathrm{cm}^{-3}$, but other atoms or groups must also deposit on the surface to form CAIs: $\mathrm{Al}, \mathrm{Ca}$, and $\mathrm{AlO}$ have concentrations which are 35,20 , and $1 / 12$ of the $O$ concentration, and so when $\mathrm{AlO}$ is involved the deposition time would be somewhat slower by perhaps a factor of 10 .

If, instead, a radius of $1000 \AA$ had been assumed for the dust particles, with the same conversion of $1 \%$ of the $\mathrm{Si}$ to dust, the total number of grains would have been 1000-fold less, but the area of each would have been 100-fold more. Thus, the total grain area per unit volume of the gas would have been tenfold less, and the process to form 5\% solids would have taken longer by a factor of 10 , which is still a short time.

\section{APPENDIX E: RATE OF OH $+\mathrm{H}_{2} \rightarrow \mathrm{H}_{2} \mathrm{O}+\mathrm{H}$, $\mathrm{OH}+\mathrm{H} \rightarrow \mathrm{O}+\mathrm{H}_{2}$ AND LIFETIME OF OH}

At $2000 \mathrm{~K}$ and $0.001 \mathrm{bar}$, the $\mathrm{OH}$ can disappear by $\mathrm{OH}$ $+\mathrm{H}_{2} \rightarrow \mathrm{H}_{2} \mathrm{O}+\mathrm{H}$, whose rate constant $k_{1}$ in standard NIST tables $^{113}$ is $\sim 9 \times 10^{-12} \mathrm{~cm}^{3}$ molecule ${ }^{-1} \mathrm{~s}^{-1}$. For the threebody reaction $\mathrm{OH}+\mathrm{H}+M \rightarrow \mathrm{H}_{2} \mathrm{O}+M$ (same tables), the rate constant is $\sim 1.5 \times 10^{-32} \mathrm{~cm}^{6}$ molecule $\mathrm{s}^{-2}$. At the prevailing pressure and $\mathrm{H}_{2} / \mathrm{H}$ ratio, one finds that it is a factor of $3 \times 10^{6}$ slower than the reaction with $\mathrm{H}_{2}$. The $k_{1}$ given above, multiplied by the $\mathrm{H}_{2}$ concentration of 4 $\times 10^{15}$ molecule $\mathrm{cm}^{-3}$, yields a lifetime of $\mathrm{OH}$ of the order of $30 \mu$ s. At $1500 \mathrm{~K}$ the lifetime of $\mathrm{OH}$ in the $\mathrm{OH}+\mathrm{H} \rightarrow \mathrm{H}$ $+\mathrm{H}_{2} \mathrm{O}$ reaction is estimated from Ref. 113 to be $60 \mu \mathrm{s}$.

The rate constant for $\mathrm{OH}+\mathrm{H} \rightarrow \mathrm{O}+\mathrm{H}_{2}$, obtained from NIST tables, ${ }^{113}$ is $\sim 5 \times 10^{-12} \mathrm{~cm}^{3}$ molecule $\mathrm{s}^{-1}$. With a concentration of $\mathrm{H}$ of $\sim 2 \times 10^{14}$ atoms cm $\mathrm{cm}^{-3}$, the probability that an $\mathrm{OH}$ will undergo this reaction is $10^{3} \mathrm{~s}^{-1}$ and so its lifetime with respect to this reaction is $1 \mathrm{~ms}$.

\section{APPENDIX F: SPIN-FORBIDDEN REACTIONS AND REDUCTION OF "FORBIDDENNESS"}

An example of a spin-forbidden transition is the photolysis from a ground state singlet to an electronically excited triplet state of the dioxide, e.g., of $\mathrm{CO}_{2}$ or $\mathrm{SiO}_{2}$. This process has been shown for $\mathrm{CO}_{2}$ to favor ${ }^{17} \mathrm{O}$ production, because the electron spin-nuclear spin coupling ("hyperfine interaction") reduces the "spin forbiddenness". ${ }^{115}$ The ${ }^{17} \mathrm{O}$ has a nuclear spin but the ${ }^{16} \mathrm{O}$ and the ${ }^{18} \mathrm{O}$ do not.

${ }^{1}$ J. H. Chen and G. J. Wasserburg, Earth Planet. Sci. Lett. 52, 1 (1981).

${ }^{2}$ A. W. Hsu, G. J. Wasserburg, and G. R. Huss, Earth Planet. Sci. Lett. 182, 15 (2000).

${ }^{3}$ M. Wadhwa and S. S. Russell, in Protostars and Planets IV, edited by V. Mannings, A. P. Boss, and S. S. Russell (University of Arizona Press, Tucson, 2000), pp. 995-1018.

${ }^{4}$ C. Allegre, Philos. Trans. R. Soc. London, Ser. A 359, 2137 (2001).

${ }^{5}$ Y. Guan, G. R. Huss, G. L. MacPherson, and G. J. Wasserburg, Science 289, 1330 (2000).

${ }^{6}$ R. N. Clayton, L. Grossman, and T. K. Mayeda, Science 182, 485 (1973).

${ }^{7}$ A. N. Krot, K. D. McKeegan, L. A. Leshin, G. J. MacPherson, and E. R. D. Scott, Science 295, 1051 (2002)

${ }^{8}$ E. R. D. Scott and A. N. Krot, Meteorit. Planet. Sci. 36, 1307 (2001).
${ }^{9}$ L. A. Leshin, A. E. Rubin, and K. D. McKeegan, Geochim. Cosmochim. Acta 61, 835 (1997)

${ }^{10}$ R. N. Clayton and T. K. Mayeda, Geochim. Cosmochim. Acta 63, 2089 (1999)

${ }^{11}$ A. E. Rubin, J. T. Wasson, R. N. Clayton, and T. K. Mayeda, Earth Planet. Sci. Lett. 96, 247 (1989).

${ }^{12}$ E. D. Young and S. S. Russell, Science 282, 452 (1998).

${ }^{13}$ C. Engrand, K. D. McKeegan, and L. A. Leshin, Geochim. Cosmochim. Acta 63, 2623 (1999).

${ }^{14}$ Y. Guan, K. D. McKeegan, and G. J. MacPherson, Earth Planet. Sci. Lett. 181, 271 (2000).

${ }^{15}$ S. S. Russell, G. J. MacPherson, L. A. Leshin, and K. D. McKeegan, Earth Planet. Sci. Lett. 184, 576 (2000)

${ }^{16}$ K. D. McKeegan, L. A. Leshin, S. S. Russell, and G. J. MacPherson, Science 280, 414 (1998).

${ }^{17}$ T. J. Fagan, K. D. McKeegan, A. N. Krot, and K. Keil, Meteorit. Planet. Sci. 36, 223 (2001).

${ }^{18}$ H. Hiyagon and A. Hashimoto, Science 282, 828 (1999).

${ }^{19}$ R. N. Clayton, Annu. Rev. Earth Planet Sci. 21, 115 (1993).

${ }^{20}$ H. Yurimoto, M. Ito, and H. Nagasawa, Science 282, 1874 (1998).

${ }^{21}$ R. N. Clayton, N. Onuma, L. Grossman, and T. K. Mayeda, Earth Planet. Sci. Lett. 34, 209 (1977).

${ }^{22}$ H. Nagahara, Meteorit. Planet. Sci. 36, 1011 (2001).

${ }^{23}$ P. Cassen, Philos. Trans. R. Soc. London, Ser. A 359, 1935 (2001).

${ }^{24}$ C. M. O. D. Alexander, A. P. Boss, and R. W. Carlson, Science 293, 64 (2001).

${ }^{25}$ A. N. Krot, A. Meibom, S. S. Russell, C. M. O. D. Alexander, T. E. Jeffries, and K. Keil, Science 291, 1776 (2001).

${ }^{26}$ D. Wark and W. V. Boynton, Meteorit. Planet. Sci. 36, 1135 (2001).

${ }^{27}$ S. S. Russell, G. R. Huss, A. J. Fahey, R. C. Greenwood, R. Hutchison, and G. J. Wasserburg, Geochim. Cosmochim. Acta 62, 689 (1998).

${ }^{28}$ H. Palme, Philos. Trans. R. Soc. London, Ser. A 359, 2061 (2001).

${ }^{29}$ A. P. Boss, Annu. Rev. Earth Planet Sci. 26, 53 (1998).

${ }^{30}$ A. Ruzicka, J. Geophys. Res. 102, 13387 (1997).

${ }^{31}$ A. P. Boss, in Chondrules and the Protoplanetary Disk, edited by R. H. Hewins, Q. H. Jones, and E. R. D. Scott (Cambridge University Press, Cambridge, 1996), pp. 257-263.

${ }^{32}$ F. H. Shu, H. Shang, M. Gounelle, A. E. Glassgold, and T. Lee, Astrophys. J. 548, 1029 (2001).

${ }^{33} \mathrm{H}$. Palme and W. V. Boynton, in Protostars and Planets III, edited by E. H. Levy and J. I. Lunine (University of Arizona Press, Tucson, 1993), pp. 979-1004.

${ }^{34}$ L. Grossman and J. W. Larimer, Rev. Geophys. Space Phys. 12, 71 (1974).

${ }^{35}$ G. J. MacPherson, D. A. Wark, and J. T. Armstrong, in Meteorites and the Early Star System, edited by J. F. Kerridge and M. S. Mathews (University of Arizona Press, Tucson, 1988), pp. 746-807.

${ }^{36} \mathrm{H}$. Y. McSween, Meteoritics 20, 523 (1985).

${ }^{37}$ A. M. Davis and G. J. MacPherson, in Chondrules and the Protoplanetary Disk, edited by Q. H. Hewins, R. H. Jones, and E. R. D. Scott (Cambridge University Press, Cambridge, 1996), pp. 71-76.

${ }^{38}$ A. N. Krot and K. Keil, Meteorit. Planet. Sci. 37, 91 (2002).

${ }^{39}$ E. R. D. Scott, S. G. Love, and A. N. Krot, in Chondrules and the Protoplanetary Disk, edited by R. H. Hewins, R. H. Jones, and E. R. D. Scott (Cambridge University Press, Cambridge, 1996), pp. 87-96.

${ }^{40}$ J. W. Larimer, J. T. Wasson, G. J. MacPherson, D. A. Wark, and J. T. Armstrong, in Meteorites and the Early Star System, edited by J. F. Kerridge and M. S. Mathews (University of Arizona Press, Tucson, 1988), pp. 395-415.

${ }^{41}$ R. H. Jones, T. Lee, H. C. Connolly, S. G. Love, and H. Shang, in Protostars and Planets IV, edited by V. Mannings, A. P. Boss, and S. S. Russell (University of Arizona Press, Tucson, 2000), pp. 927-961.

${ }^{42}$ A. E. Rubin, B. Fegley, and R. Brett, in Meteorites in the Early Solar System, edited by J. F. Kerridge and M. S. Mathews (University of Arizona Press, Tucson, 1988), pp. 488-511.

${ }^{43}$ A. N. Krot, B. Fegley, K. Lodders, and H. Palme, in Protostars and Planets IV, edited by V. Mannings, A. P. Boss, and S. S. Russell (University of Arizona Press, Tucson, 2000), pp. 1019-1054.

${ }^{44}$ D. S. Ebel and L. Grossman, Geochim. Cosmochim. Acta 64, 339 (2000).

${ }^{45}$ L. Grossman, D. S. Ebel, S. B. Simon, A. M. Davis, F. M. Richter, and N. M. Parsad, Geochim. Cosmochim. Acta 64, 2879 (2000).

${ }^{46}$ J. A. Wood and A. Hashimoto, Geochim. Cosmochim. Acta 57, 2887 (1993).

${ }^{47}$ S. Yoneda and L. Grossman, Geochim. Cosmochim. Acta 59, 3413 (1995).

${ }^{48}$ O. Navon and G. J. Wasserburg, Earth Planet. Sci. Lett. 73, 1 (1985). 
${ }^{49}$ R. N. Clayton, Nature (London) 415, 860 (2002).

${ }^{50}$ M. H. Thiemens, Science 219, 1073 (1983).

${ }^{51}$ M. H. Thiemens, in Chondrules and the Protoplanetary Disk, edited by R. H. Hewins, R. H. Jones, and E. R. D. Scott (Cambridge University Press, Cambridge, 1996), pp. 107-118.

${ }^{52}$ D. D. Clayton, Astrophys. J. 334, 191 (1988).

${ }^{53}$ K. D. McKeegan (private communication).

${ }^{54}$ J. R. Lyons and E. D. Young, Proceedings of XXXIV Lunar and Planetary Science Conference, Abstract 1981, 2003.

${ }^{55}$ J. E. Heidenreich and M. H. Thiemens, J. Chem. Phys. 78, 892 (1983).

${ }^{56}$ M. H. Thiemens, Science 283, 341 (1999).

${ }^{57}$ R. E. Weston, Chem. Rev. (Washington, D.C.) 99, 2115 (1999).

${ }^{58}$ K. Mauersberger, D. Krankowsky, C. Janssen, and R. Schinke, Adv. At. Mol. Opt. Phys. (to be published).

${ }^{59}$ J. Yang and S. Epstein, Geochim. Cosmochim. Acta 51, 2011 (1987).

${ }^{60}$ B. C. Hathorn and R. A. Marcus, J. Chem. Phys. 111, 4087 (1999).

${ }^{61}$ B. C. Hathorn and R. A. Marcus, J. Chem. Phys. 113, 9497 (2000).

${ }^{62}$ Y. Q. Gao and R. A. Marcus, Science 293, 259 (2001).

${ }^{63}$ Y. Q. Gao and R. A. Marcus, J. Chem. Phys. 116, 137 (2002).

${ }^{64}$ Y. Q. Gao, W. C. Chen, and R. A. Marcus, J. Chem. Phys. 117, 1536 (2002).

${ }^{65}$ S. M. Anderson, D. Huelsebusch, and K. Mauersberger, J. Chem. Phys. 107, 5385 (1998).

${ }^{66}$ J. Güenther, B. Erbacher, D. Krankowsky, and K. Mauersberger, Chem. Phys. Lett. 306, 209 (1999).

${ }^{67}$ C. Janssen, J. Güenther, D. Krankowsky, and K. Mauersberger, J. Chem. Phys. 111, 7179 (1999).

${ }^{68}$ J. Güenther, D. Krankowsky, and K. Mauersberger, Chem. Phys. Lett. 324, 31 (2000).

${ }^{69}$ M. H. Thiemens and T. Jackson, Geophys. Res. Lett. 17, 717 (1990).

${ }^{70}$ J. Morton, J. Barnes, B. Schueler, and K. Mauersberger, J. Geophys. Res. 95, 901 (1990).

${ }^{71}$ J. Morton, B. Schueler, and K. Mauersberger, Chem. Phys. Lett. 154, 143 (1989).

${ }^{72}$ K. Mauersberger, Geophys. Res. Lett. 14, 80 (1987).

${ }^{73}$ K. Mauersberger, J. Morton, B. Schueler, J. Stehr, and S. M. Anderson, Geophys. Res. Lett. 20, 1031 (1993).

${ }^{74}$ D. Krankowsky and K. Mauersberger, Science 274, 1324 (1996).

${ }^{75}$ K. Mauersberger, B. Erbacher, D. Krankowsky, J. Güenther, and R. Nickel, Science 283, 370 (1999).

${ }^{76}$ E. Stolper, Geochim. Cosmochim. Acta 46, 2159 (1982).

${ }^{77}$ J. R. Beckett and E. Stolper, Meteoritics 29, 41 (1994).

${ }^{78}$ F. Robert, Second International Symposium on Isotopomers (ISI) Stresa, Italy, 4-7 Nov. 2003.

${ }^{79}$ M. H. Thiemens, R. Nelson, and Q. W. Ding, Proceedings of the XXV Lunar and Planetary Science Conference, Abstract 1398, 1994.

${ }^{80} \mathrm{R}$. Nelson, M. Thiemens, J. Nuth, and B. Donn, Proceedings of the XIX Lunar Planetary Science Conference, Abstract 559, 1989.

${ }^{81}$ M. Slack and A. Grillo, Combust. Flame 59, 189 (1985).

${ }^{82}$ W. C. Chen and R. A. Marcus (unpublished). Thermodynamic results were largely obtained from Janaf Thermodynamic Tables http:// webbook.nist.gov/chemistry/form-ser.html using solar abundances in Refs. 84 and 85 . In some cases, such as for $\mathrm{Si}(\mathrm{OH})_{2}$ the results were supplemented by electronic structure calculations.

${ }^{83}$ G. Vidali, J. E. Roser, G. Manico, and V. Pirronello, Adv. Space Res. 33, 6 (2004).
${ }^{84}$ K. Lodders, Astrophys. J. 591, 1220 (2003).

${ }^{85}$ E. Anders and N. Grevesse, Geochim. Cosmochim. Acta 53, 197 (1989).

${ }^{86}$ R. H. Nichols, R. T. Grimaldi, and G. J. Wasserburg, Meteorit. Planet. Sci. 33, A155 (1998).

${ }^{87}$ The smallness of those contributions is seen from the small heights of the white boxes in Fig. 7 in Ref. 63 for isotopologues which are not purely symmetric and from $1 / 3$ the height of the boxes for the purely symmetric species $\mathrm{OOO}$ and $Q Q Q$.

${ }^{88}$ A. E. Nielsen, Pure Appl. Chem. 53, 2025 (1981).

${ }^{89}$ A. E. Nielsen, J. Cryst. Growth 67, 289 (1984).

${ }^{90}$ P. P. Chang and M. D. Donahue, J. Colloid Interface Sci. 122, 230 (1988).

${ }^{91}$ W. K. Burton, N. Cabrera, and F. C. Frank, Proc. R. Soc. London B243, 299 (1951).

${ }^{92}$ J. Zhang and G. H. Nancollas, J. Colloid Interface Sci. 200, 131 (1998).

${ }^{93}$ A. Tsuchiyama, S. Tachibana, and T. Takahashi, Geochim. Cosmochim. Acta 63, 2451 (1999).

${ }^{94}$ T. Sata, T. Sasamoto, H. L. Lee, and E. Maeda, Rev. Int. Haates Temp. Refract. 15, 237 (1978).

${ }^{95}$ R. A. Marcus (unpublished).

${ }^{96}$ J. P. Hirth and G. M. Pound, in Condensation and Evaporation, Nucleation and Growth Kinetics (Pergamon, Oxford, 1963), pp. 123-124.

${ }^{97}$ H. Hertz, Ann. Phys. (Leipzig) 17, 193 (1882).

${ }^{98}$ M. Knudsen, Ann. Phys. (Leipzig) 47, 697 (1915).

${ }^{99}$ A. Tsuchiyama, T. Takahashi, and S. Tachibana, Mineral. J. 20, 113 (1998).

${ }^{100} \mathrm{H}$. Inaba, S. Tachibana, H. Nagahara, and K. Ozawa, Proceedings of the XXXII Lunar and Planetary Science Conference, Abstract 1837, 2001.

${ }^{101}$ C. M. Stevens, L. Kaplan, R. Gorse, S. Durkee, M. Compton, S. Cohen, and K. Bielling, Int. J. Chem. Kinet. 12, 935 (1980).

${ }^{102}$ A. Hashimoto, Nature (London) 347, 53 (1990).

${ }^{103}$ T. Rockmann, C. Brenninkmeijer, G. Saveressig, P. Begmaschi, J. Crowley, H. Fischer, and P. Crutzen, Science 281, 544 (1998).

${ }^{104}$ A. K. Huff and M. H. Thiemens, Geophys. Res. Lett. 25, 3509 (1998).

${ }^{105}$ S. K. Bhattacharya and M. H. Thiemens, Z. Naturforsch. A 44A, 811 (1989).

${ }^{106}$ D. Charlo and D. C. Clary, J. Chem. Phys. 120, 2700 (2004).

${ }^{107}$ D. Babikov, B. K. Kendrich, R. B. Walker, R. T. Pack, P. Fleurat-Lesard, and R. Schinke, J. Chem. Phys. 118, 6298 (2003), and references cited therein.

${ }^{108}$ In the ozone system in Refs. 60-64, there are three terms in the equation corresponding to Eq. (10), the third arising from $\mathrm{OQO}$ in the ozone. This difference only reduces the result of the $\eta$ effect. In particular, the $\eta$ of 1.15 corresponded to an $R$ of $\approx[(1.15)(2 / 3)+1.0 / 3]$, i.e., 1.10 or 10 parts per mil.

${ }^{109}$ G. B. Stringfellow, in Crystal Growth, edited by B. R. Pamplin (Pergamon, Oxford, 1980), pp. 181-220.

${ }^{110}$ R. Z. Bachrach, in Crystal Growth, edited by B. R. Pamplin (Pergamon, Oxford, 1980), pp. 221-274.

${ }^{111} \mathrm{M}$. H. Thiemens (private communication).

${ }^{112}$ F. Turatti, D. W. T. Griffith, S. R. Wilson, M. B. Esler, T. Rahn, H. Zhang, and G. A. Blake, Geophys. Res. Lett. 27, 2489 (2000).

${ }^{113}$ See http://kinetics.nist.gov/index.php, http://kinetics.nist.gov/index.php

${ }^{114}$ B. T. Draine, Astrophys. J. 598, 1026 (2003).

${ }^{115}$ S. E. Bhattacharya, J. Savarino, and M. H. Thiemens, Geophys. Res. Lett. 27, 1459 (2000). 